\title{
Ds mapas nos livros didáticos de Geografia
}

\section{Maps in Geography textbooks}

Fernando da Silva Alves* Fernando Shinji Kawakubo** Felipe Gomes Rubira***

\section{Resumo:}

O presente estudo tem como objetivo estabelecer uma discussão acerca dos mapas presentes em dois livros didáticos utilizados no primeiro e segundo ano do ensino médio de geografia no Estado de Minas Gerais. Três critérios foram adotados na análise dos mapas. Inicialmente foi feito uma análise exploratória dos documentos cartográficos existentes, onde foi adotada a metodologia de Bertin (1977) e Martinelli (2003) para a classificação dos mapas. Em seguida, os mapas selecionados foram analisados levando em consideração os elementos da comunicação visual e proposições, quando necessárias, foram sugeridas com o intuído de melhorar a percepção das informações contidas nos mapas. Finalmente, foi analisada a conexão do conteúdo teórico com as informações dos mapas apresentados. Esta etapa foi importante porque permitiu avaliar a real funcionalidade do mapa no ensino de geografia contido nos dois livros selecionados. Os resultados mostraram que no geral, os mapas são bem apresentados e que há um forte desequilíbrio de métodos cartográficos empregados. Infelizmente, também foi observada uma fraca conexão do conteúdo teórico com os mapas apresentados, sendo estes mais utilizados como instrumento de localização do que de comunicação visual.

\begin{abstract}
:
This study aims to establish a discussion about the maps presented in two textbooks used in the first and the second year of high school geography in the state of Minas Gerais. We adopted three criteria to analyze those maps. First, to classify the maps, an exploratory analysis was performed by using as reference the methodology proposed by Bertin (1977) and Martinelli (2003). Then, the selected maps were analyzed taking into account the basic elements of visual communication, and, when necessary, propositions were made intending to improve their visual perceptions. Finally, the relation between theoretical content and information featured in the maps was evaluated. It is important to clarify that this last step was particularly important because it allowed us to understand the real functionality of the maps in the two textbooks. The results showed that, in general, the maps are well illustrated, but there is a strong unbalance of cartographic methods used for representing the geographical phenomenon. Unfortunately, we also noted a weak connection between theoretical content and cartography, being the maps more used as a tool for location than for visual communication.
\end{abstract}

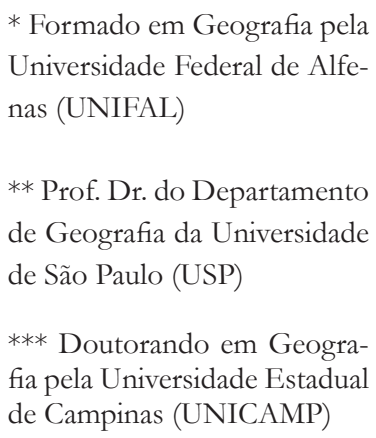
Universidade Federal de Alfenas (UNIFAL)

** Prof. Dr. do Departamento de Geografia da Universidade de São Paulo (USP)

*** Doutorando em Geografia pela Universidade Estadual de Campinas (UNICAMP)

\section{Palavras-chave:}

Produtos cartográficos, Ensino de Geografia, Comunicação visual

Key-Words:

Cartographic products, Geography teaching, Visual communication 


\section{INTRODUÇÃO}

A cartografia como instrumento de comunicação no ensino é uma importante ferramenta para o professor, principalmente para o ensino de geografia. Os mapas estão presentes em vários meios de comunicação atuais, seja nos jornais, na televisão, na internet e nos celulares que fazem parte do cotidiano dos jovens e das crianças.

Neste contexto, falar em geografia é falar em mapas. "Quando falamos em mapas, imediatamente os associamos à geografia. É um aspecto eminentemente cultural. Os mapas, portanto, representariam a geografia, o que é geográfico, eles seriam a própria geografia. Sinônimos" (MARTINELLI, 2003, p.1). Esta afirmação resume a importância que o mapa tem para a ciência geográfica, e ao mesmo tempo ressalta a necessidade de serem bem confeccionados.

Para que os mapas cumpram seu papel de comunicação espacial, torna-se necessário seguir alguns parâmetros. Algumas convenções cartográficas já estabelecidas devem ser adotadas a fim de melhorar o fluxo de informação e a estética desse importante instrumento. O livro didático como principal aliado do professor deve ser bem estruturado e atrativo aos alunos, de modo que no decorrer do ano letivo, o interesse pela geografia seja cada vez mais despertado.

Os Parâmetros Curriculares Nacionais - PCN's (BRASIL, 2000) e as Orientações Complementares aos Parâmetros Curriculares Nacionais para o Ensino Médio - PCN+ (BRASIL, 2002) oferecem orientações educacionais aos professores, com o objetivo de auxiliá-los a implementar as reformas no ensino definidas pela Lei de Diretrizes e Bases da Educação Nacional - LDB (BRASIL, 1996). Assim como os PCN's surgiram como forma de orientar os trabalhos dos professores, os livros didáticos também. Torna-se então necessária uma análise dos materiais que acompanham o professor durante o ano letivo.

Os textos contidos nos livros didáticos devem explorar adequadamente os mapas que os acompanham, a fim de torná-los um componente do próprio texto teórico e não somente uma ilustração.

A presente pesquisa será realizada mediante a análise de documentos cartográficos presentes nos livros alvos deste trabalho, baseando-se nos estudos de Bertin (1967) e Martinelli (2003). A leitura dos livros e artigos produzidos por esses autores servirão de base para a comparação entre a metodologia utilizada por eles na confecção de mapas temáticos e a metodologia utilizada na confecção dos livros didáticos.

A princípio, será realizada uma revisão dos Parâmetros Curriculares Nacionais, verificando qual a sua função e sua relação com a disciplina de geografia. Logo após, serão revistos os métodos cartográficos já consagrados na cartografia temática, segundo a metodologia proposta por Bertin (1967) e Martinelli (2003).

Os livros "Fronteiras da Globalização 1: O mundo natural e o espaço humanizado" e "Fronteiras da Globalização 2: O espaço geográfico globalizado", serão utilizados como livros de referência, onde foram selecionados alguns mapas para a análise, os quais englobassem diferentes propriedades perceptivas e métodos de representação.

Portanto, o objetivo do presente estudo consiste em analisar os principais mapas e cartogramas publicados nos dois volumes dos livros Fronteiras da Globalização de autoria de Lúcia Marina Alves de Almeida e Tércio Barbosa Rigolin.

Nos resultados, foram dispostos alguns mapas de ambos os livros com diferentes metodologias empregadas, e no caso de "falhas metodológicas", aponta-se sugestões para a melhoria da comunicação visual.

Com relação aos conteúdos teóricos do livro, foram verificados se os mesmos exploram de maneira adequada os mapas que os acompanham. O critério adotado na adequação do conteúdo teórico consistiu na conexão da informação contida e transmitida pelo mapa e o texto apresentado.

Essa pesquisa justifica-se em razão do ensino médio ser a última etapa dos estudos antes do ingresso nas universidades, uma escolha que fará a diferença na vida dos estudantes. Então, o comprometimento do professor e o contato com materiais didáticos de qualidade influenciarão no interesse dos alunos pela própria disciplina geográfica, fomentando a formação de novos geógrafos e também de cidadãos mais críticos e comprometidos com a busca de soluções para os anseios da sociedade como um todo. A importância do presente estudo deve-se também ao fato dos livros mencionados terem sido selecionados por uma comissão de professores, para serem trabalhados na Escola Estadual Dr. Napoleão Salles na cidade de Alfenas, Sul de Minas Gerais.

Entende-se que a cartografia constitui um instrumento primordial no entendimento de fenômenos geográficos. Portanto, é de suma importância que os métodos 
empregados na comunicação visual sejam utilizados de maneira eficiente como forma de revelar os padrões e arranjos espaciais dos elementos sociais, políticos e naturais contidos nos mapas e no ensino da disciplina geográfica.

\section{OS PARÂMETROS CURRICULARES NACIO- NAIS (PCN'S) E A GEOGRAFIA}

O Ensino Médio vem passando por diversas transformações a partir da criação da Lei de Diretrizes e Bases da Educação Nacional, lei no 9.394, de 20 de Dezembro de 1996. Ao invés de somente preparar o aluno para o mercado de trabalho ou para o prosseguimento dos estudos em nível superior, como ocorria anteriormente, agora as escolas devem prepará-los não só para a vida profissional como também social. Isso significa torná-los cidadãos críticos, pensantes, que saibam analisar e interpretar os fenômenos que ocorrem ao seu redor e propor soluções para os problemas do seu dia-a-dia.

O art. 35, inciso II da Lei de Diretrizes e Bases da Educação Nacional de 1996 estabelece a finalidade do Ensino Médio:

Art. 35. O ensino médio, etapa final da educação básica, com duração mínima de três anos, terá como finalidades:

[...] II - a preparação básica para o trabalho e a cidadania do educando como pessoa humana, incluindo a formação ética e o desenvolvimento da autonomia intelectual e do pensamento crítico (BRASIL, 1996, p. 13-14).

Nesse contexto, a geografia tem um papel fundamental, pois a disciplina trata dos diversos fatores que afetam diretamente a vida das pessoas como o desemprego, a má distribuição de renda, distância dos grandes centros e a desigualdade social.

Na geografia, destaca-se também o papel da cartografia como instrumento de linguagem visual, que permite a espacialização dos fenômenos geográficos. Além de auxiliar na compreensão de fatos que afetam a vida da população, a cartografia também se preocupa com o entendimento do espaço, contemplando o aspecto dinâmico da geografia, como nos atenta o PCNEM (2002) quanto às habilidades e competências a serem desenvolvidas em Geografia por meio da representação e comunicação, investigação e compreensão, contextualização sócio-cultural, competências que podem ser proporcionadas por meio do auxílio de mapas e de técnicas cartográficas.

Com o intuito de auxiliar as escolas a aplicar o que preconiza a Lei de Diretrizes e Bases da Educação Nacional, reuniram-se professores universitários, dirigentes e a equipe técnica da Secretaria de Educação Média e Tecnológica de onde, após várias reuniões, foram elaborados os PCN's, que servem de base para a organização curricular dos estabelecimentos de ensino.

Tal documento define competências e habilidades que os alunos deverão desenvolver dentro de cada área/ disciplina oferecida no Ensino Médio. Em particular, no ensino de geografia, o PCN + contempla três competências a serem trabalhadas e desenvolvidas com os alunos:

- Representação e comunicação.

- Investigação e compreensão.

- Contextualização sociocultural.

Dentre tais competências, as mais voltadas à cartografia são a representação e comunicação, as quais cabem ao aluno:

- Ler, analisar e interpretar os códigos específicos de Geografia (mapas, gráficos, tabelas e etc.) considerando-os como elementos de representação de fatos e fenômenos espaciais ou espacializados.

- Reconhecer e aplicar o uso das escalas cartográfica e geográfica como formas de organizar e conhecer a localização, a distribuição e a frequência dos fenômenos naturais e humanos (BRASIL, 2002, p. 60).

É importante que o aluno saiba identificar e representar os fenômenos que afetam a sociedade e a si mesmo através dos mapas, bem como a se localizar através dessa importante ferramenta, mas para que o seu interesse seja despertado, é imprescindível que o material que o acompanha nos estudos, o livro didático, seja atrativo.

É por meio dele que geralmente os alunos terão seus primeiros contatos com os mapas, por isso a importância de que os livros sejam bem elaborados e que os métodos utilizados sejam aplicados de maneira correta, possibilitando a reflexão dos alunos perante os fenômenos representados.

Para que a competência de representação seja desenvolvida, torna-se necessário então o conhecimento sobre as metodologias empregadas na elaboração dos mapas e cartogramas utilizadas na representação dos mais diversos fenômenos estudados pela geografia.

\section{OS MÉTODOS CARTOGRÁFICOS}

A cartografia sempre teve papel importante na geografia, seja para auxiliar na navegação, na sistematização do conhecimento geográfico, na delimitação do territó- 
rio, no entendimento regional da distribuição da população, na análise de fluxos ou no auxílio de soluções para os problemas contemporâneos.

A cartografia pode ser dividida em duas grandes áreas: a cartografia sistemática e a cartografia temática. A cartografia sistemática preocupa-se com a definição de referenciais geodésicos, mapeamentos sistemáticos de base, projeções e definições de posicionamento, transporte de coordenadas e de altitude entre outros. A cartografia temática, por sua vez, foca na representação dos temas, objeto do presente estudo.

A cartografia temática é uma metodologia de representação de caráter monossêmico, ou seja, apresenta apenas um único significado. De acordo com Bertin (1967) e Martinelli (2003), a tarefa essência da cartografia temática é transcrever as três relações fundamentais entre os objetos: a diversidade, a ordem e a proporcionalidade. Estas três relações fundamentais são exploradas por meio das propriedades perceptivas que a cartografia temática adota, que pode ser seletiva $(\neq)$, associativa $(\equiv)$, ordenada (O) e quantitativa (Q). A Figura 1 ilustra relação existente entre a percepção e as formas de representação.

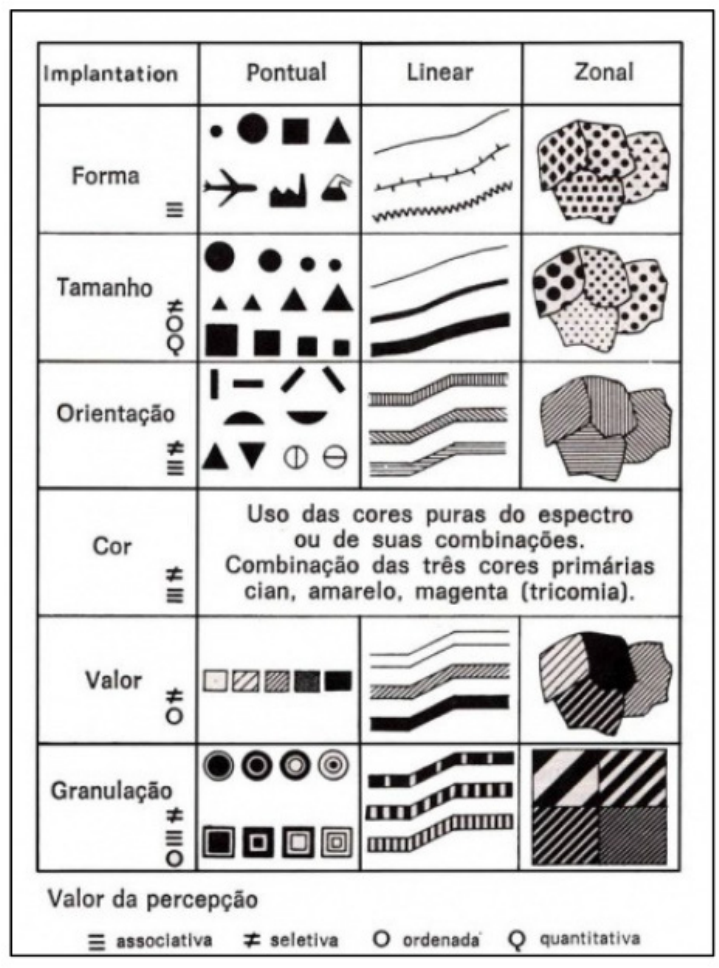

Figura 1: Quadro de variáveis visuais.

Fonte: JOLY, F. (2005, p.73)

A propriedade seletiva tem como objetivo isolar classes distintas, dando ênfase a diferenciação entre obje- tos ou fenômenos. A percepção associativa tem a finalidade de facilitar a comunicação visual agrupando classes em categorias. Já a propriedade ordenada estabelece uma ordenação entre os objetos com o objetivo de evidenciar algum nível hierárquico espacial ou cronológico. Por fim a percepção quantitativa fornece a relação de proporcionalidade.

Os elementos mais utilizados como variáveis visuais para expressar as percepções mencionadas são: a cor, que e refere a reflexão da energia em um determinado comprimento de onda do visível; o valor, que explora a tonalidade de uma mesma cor; o tamanho, que fornece a ideia de dimensão e proporcionalidade; a granulação, que fornece os elementos texturais; a orientação, que pode ser vertical, horizontal ou obliqua; e por fim, a forma, podendo ser um círculo, quadrado, retângulo ou outras formas complexas como elementos pictóricos.

É importante frisar que o raciocínio chave levado em consideração na cartografia temática é utilizar as variáveis visuais em harmonia com a percepção e vice-versa. Ou seja, para percepção seletiva, adota-se variáveis visuais com cores ou formas discretas. A percepção ordenada requer o uso de variáveis visuais que remetem a algum ordenamento, como sequência de cores, tonalidades de uma mesma cor (valor) ou granulações. Já a percepção quantitativa requer que o tamanho de uma determinada figura geométrica seja proporcional à grandeza numérica absoluta do tema tratado.

A literatura especializada descreve vários métodos de representação da cartografia temática. De acordo com Martinelli (2003), os métodos de representação podem ser agrupados em 4 grupos: representação qualitativa, representação ordenada, representação quantitativa e representação dinâmica.

As representações qualitativas exploram as percepções seletiva/associativa.

Em mapas geológicos de minério (metálicos e não metálicos) contendo ferro, bauxita, manganês, areia e pedra, estes elementos podem ser representados em um único mapa utilizando símbolos (formas geométricas) diferenciados ou por meio de vários cartogramas denominado de coleções de mapa. Na primeira metodologia, comumente referido como mapa exaustivo, todos os elementos são dispostos em uma única legenda, gerando um mapa de difícil interpretação em razão da grande quantidade de informações, gerando muitas vezes um mapa poluído. Cada minério é representado por um símbolo 
diferente ou uma cor.

As representações qualitativas também são muito utilizadas em mapas de uso da terra e cobertura vegetal, conforme o exemplo já mencionado. Quando o cartógrafo tem interesse de enfatizar as diferenciações entre as classes mapeadas, cores distintas (cores frias e quentes) são utilizadas na sequência da legenda do mapa dando ênfase de que cada classe é independente da outra.

Para reforçar tal percepção, a legenda segue uma sequência de caixas separadas com o objetivo de evidenciar a independência entre as classes. Assim, áreas de mata podem ser representadas, por exemplo, pela cor verde escuro, os cerrados com a cor amarela, a agricultura com a cor verde claro e as áreas urbanas com a cor vermelha. Como forma de explorar melhor a diferenciação de cores, é comum a adoção de cores complementares (cores opostas no círculo de cores) na sequência da legenda. A Figura 2 ilustra o círculo de cores com as duas harmonias: as cores complementares e as cores análogas.

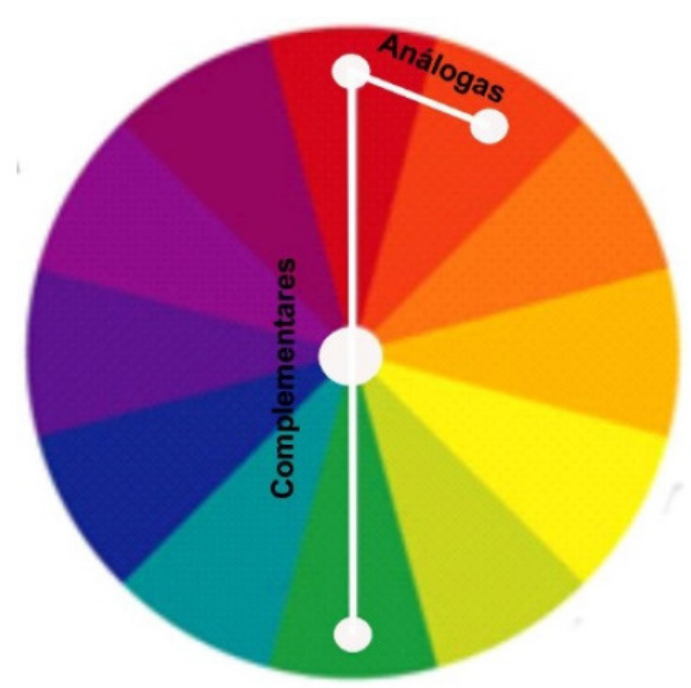

Figura 2: Círculo de cores.

Fonte: Elaboração dos autores

Outro exemplo de representação qualitativa são os mapas de estradas. A representação do tipo de vias pode ser feita por meio de linhas continuas ou tracejadas ou por meio de cores. De maneira análoga, pode-se representar as informações planimétricas de um determinado Estado utilizando a cor azul para a hidrografia, a cor vermelha para as estradas e a cor marrom para as ferrovias.

Mapas geológicos podem utilizar diferentes cores para as unidades de rochas. Assim, rochas sedimentares podem ser classificadas com a cor verde, rochas ígneas com a cor vermelha e metamórficas com a cor ciano. estabelecer cronologia, ordem e hierarquia. Assim, adota-se comumente cores análogas como forma de evidenciar a continuidade do fenômeno. No caso dos mapas geológicos, por exemplo, estes podem ser classificados quanto à cronologia das rochas. Assim, rochas mais antigas recebem cores mais quentes e rochas mais novas com cores menos quentes. É importante esclarecer que as cores aqui definidas nos dois exemplos apresentados não seguem as normatizações da cartografia geológica que são padronizadas.

Outro exemplo clássico de representação ordenada é o método de sinatropização. Classes de uso da terra e de cobertura vegetal mais "natural" são representadas por cores mais frias e classes mais "antrópicas" por cores mais quentes. Assim, as áreas de mata são representadas por verde escuro, o cerrado com verde claro, os pastos em cinza, a agricultura em laranja e as áreas urbanas em vermelho. Podendo o cartógrafo optar por uma legenda de caixa contínua. No caso de mapas de rodovias utilizando as representações ordenadas, os sistemas viários podem ser organizados de acordo com a infraestrutura: ou seja, as estradas pavimentadas com a cor vermelho escuro, as rodovias não pavimentadas com a cor laranja e os caminhos pela cor amarela. Diferentemente da representação qualitativa, no método ordenado a ênfase é dada na organização dos temas.

Os métodos de representação quantitativos trabalham com variáveis numéricas como os de figuras geométricas proporcionais, os de pontos de contagem, o método coroplético e o método isarítimico.

O método de figuras geométricas proporcionais é muito utilizado para a representação de valores absolutos de população. Neste método, o valor da população por unidade administrativa é representada de maneira proporcional ao tamanho do círculo. Assim, municípios com maior população recebem tamanhos de círculos maiores e os municípios de menor população são representados por círculos proporcionais aos valores expressos.

Uma maneira bastante utilizada para enriquecer o mapa de círculos proporcionais é definir a proporção de homens de mulheres por meio de um setograma. O setograma define por meio de um gráfico de pizza a proporção masculina e feminina podendo ser expressa pela cor azul e vermelho (cores distintas evidenciando a independência das classes). De maneira análoga pode-se representar a quantidade de veículos que trafega nas rodovias. A largura das rodovias é proporcional ao valor de números de carros que nela trafegam. Tal metodologia é muito eficiente para representação de fluxos e mostra o nível de dependência entre as regiões. 
Para a representação pontual de fenômenos quantitativos utiliza-se o método de pontos de contagem, também conhecido como de nuvens de pontos. Ao invés de criar círculos proporcionais ao valor, adota-se determinados números de pontos distribuídos espacialmente no mapa. Estes pontos são alocados, de preferência, nas áreas de maior ocorrência do fenômeno. Tomando como exemplo a distribuição de bovinos de uma determinada unidade federativa, cada ponto recebe um determinado valor. $\mathrm{O}$ valor adotado para cada ponto deve ser suficiente para gerar um número de pontos que distribuídos espacialmente crie uma visualização de nuvem no mapa.

O método de ponto de contagem é muito eficiente na análise espacial da distribuição de eventos, pois fornece uma ideia de distribuição do evento dentro da unidade de área analisada, diferentemente do método de círculo proporcional que fornece o valor total por unidade de área.

O método coroplético é dedicado à representação zonal (área) de valores relativos, ou seja, taxas. Os mapas de densidade populacional são exemplos clássicos que fazem uso do método coroplético. Assim, áreas com maiores densidades populacionais podem ser representadas pela cor vermelha com tonalidades escuras e as áreas de menor densidade demográfica por cores vermelhas com tonalidades mais claras.

As representações isarítimicas têm como finalidade representar fenômenos espaciais contínuos, como chuva (isoietas), temperatura (isotermas), umidade, profundidade de camadas sedimentares etc. Por se tratar de fenômenos contínuos, utiliza-se normalmente a variável valor (tonalidades de uma mesma cor) com legenda de caixas juntas. Os dados de chuva, temperatura e umidade, por exemplo, são normalmente fornecidos por estações climatológicas distribuídas geograficamente.

O método de estimar valores em áreas não contempladas pela amostragem é conhecido como interpolação espacial. Tomando como o exemplo a distribuição de chuva, a forma manual de realizar tal tarefa é criar linhas de igual valor entre os pontos amostrados. Caso dois pontos vizinhos tenham valores acumulados de chuva de $1000 \mathrm{~mm}$. e $2000 \mathrm{~mm}$., a curva a ser traçada poderá receber valor de 1500 no ponto médio de distância entre os dois pontos mencionados. Outro critério adotado é evitar que as linhas se cruzam. Apesar de esta regra ser bastante simples, critérios subjetivos muitas vezes são adotados e a qualidade do mapeamento depende da experiência do intérprete. Em áreas de relevo mais acentuado, a pluviosidade tende a ser maior. Por- tanto, a simples distância geométrica muitas vezes não é eficiente para representar tal variação.

Finalmente as representações dinâmicas evidenciam as transformações na paisagem ao longo do tempo e no espaço (MARTINELLI, 1991). O avanço do desmatamento na Amazônia, por exemplo, ao longo dos anos, pode ser representado de diferentes formas. Uma maneira bastante simples e rápida de visualizar o incremento do desmatamento é por meio de coleção de mapas. Para cada cartograma disposto na sequência dos anos, representa-se por meio de uma cor as manchas do desmatamento.

Outro ponto importante que deve ser mencionado é a diferença entre mapas analíticos e de síntese. A ótica analítica foca nos elementos constituintes por meio de sobreposição de temas. As cartas topográficas, por exemplo, são exemplos de cartas analíticas onde as informações de curvas de nível, pontos cotados e informações planimétricas são sobrepostas as informações altimétricas.

Já no caso da cartografia de síntese, privilegia-se a combinação ou fusão de temas. De acordo com Archela e Théry (2008) o mapa de síntese é mais complexo e exige profundo conhecimento técnico dos assuntos a serem mapeados. Representam o mapeamento da integração de fenômenos. Ainda segundo Archela e Théry (2008) o mapa de síntese é construído para mostrar ao leitor as relações existentes entre vários dados, tal como sua eventual aptidão para determinar conjuntamente outros fenômenos ou outras combinações. Como exemplo de mapas de síntese pode-se citar os mapas que expressam os setores produtivos primários, secundários e terciários assim como os mapas de zoneamento.

\section{METODOLOGIA}

Para a realização do presente estudo, foram selecionados por meio de amostragem intencional dois livros didáticos utilizados no primeiro e segundo anos do ensino médio na rede pública do município de Alfenas, Sul do Estado de Minas Gerais, livros os quais são denominados Fronteiras da Globalização 1: O mundo natural e o espaço humanizado e Fronteiras da Globalização 2: O espaço geográfico globalizado, de Lúcia Marina Alves de Almeida e Tércio Barbosa Rigolin.

Os livros foram escolhidos intencionalmente (estudo de caso), por serem os livros utilizados na Escola Estadual 
Dr. Napoleão Salles e essa ter o vinculo com os pesquisadores por meio dos estágios obrigatórios da Universidade Federal de Alfenas (UNIFAL) e do Programa Institucional de Bolsa de Iniciação à Docência (PIBID). Portanto, a escotha destes livros ocorreu por terem sido selecionados pelos professores da escola para serem trabalhados com os alunos durante os anos de 2015, 2016.

Os livros apresentam vários mapas que ilustram os diversos assuntos tratados durante a apresentação de seu conteúdo, o que auxilia os alunos a identificarem onde ocorrem os fenômenos. Por isso a importância de que os mapas estejam utilizando as metodologias de forma correta e clara facilitando sua compreensão.

A análise dos livros, volumes 1 e 2, ocorreu mediante três etapas. Inicialmente será feita uma análise exploratória dos documentos cartográficos existentes nos livros. Os critérios a serem adotados levam em consideração os elementos norteadores da interpretação dos mapas temáticos segundo a metodologia de Bertin (1967) e Martinelli (2003). Deste modo será considerado o método de percepção, de representação e de implantação.

Num segundo momento foi verificado se a metodologia está sendo bem utilizada, ou seja, se está de acordo com as convenções cartográficas já estabelecidas por Bertin (1967) e Martinelli (2003) e caso não estejam, serão sugeridas alterações para a melhora da comunicação visual.

Por fim, na terceira etapa, serão analisados os textos que acompanham os mapas, verificando se estes os exploram e não somente ilustram o assunto tratado.

A presente metodologia parte do princípio de que o mapa constitui um importante instrumento de comunicação visual que auxilia na aprendizagem do aluno, pois estimula outros sentidos por meio da visão.

\section{RESULTADOS E DISCUSSÃO}

No livro Fronteiras da Globalização 1: O mundo natural e o espaço humanizado, foram encontrados 27 mapas, 11 utilizando a propriedade perceptiva seletiva, 2 utilizando a percepção ordenada, 10 utilizando a percepção quantitativa e 4 utilizando a percepção mista (Quadro 1).

Para a propriedade perceptiva seletiva, os principais mapas empregados são os mapas corocromáticos, de manifestação pontual e de manifestação linear. Tratam-se dos métodos que abordam a maior diversidade de temas, que inclui questões urbanas, geopolítica e fenômenos naturais relacionados com os elementos físicos da paisagem como relevo, solo, clima, rocha, vegetação e hidrografia. Na per- cepção ordenada, fenômenos dinâmicos e cronológicos são explorados utilizando-se mapas corocromáticos, de manifestações pontuais e lineares. Dois temas são abordados, sendo o avanço da desertificação no mundo e a área ocupada por Israel ao longo dos anos. Na percepção quantitativa, 4 métodos clássicos da cartografia temática são abordados com temas diversificados. No método coroplético, são explorados a disponibilidade de água no mundo e a mortalidade infantil/expectativa de vida no mundo. O método isarítimico foi utilizado, basicamente, para a representação de fenômenos naturais, como terremotos, altimetria, temperatura e precipitação. Para os mapas de pontos de contagem, foi observado apenas um mapa, abordando a distribuição da população no mundo e para as figuras geométricas proporcionais também apenas um, se tratando das principais aglomerações urbanas por população. Por fim as propriedades perceptivas mistas exploram ao mesmo tempo diferentes percepções com implantações variadas, utilizando ponto, linha e área. Dentre os temas abordados são destacados os temas relacionados com imigrações.

No livro Fronteiras da Globalização 2: O espaço geográfico globalizado, foram encontrados 38 mapas, 26 utilizando a propriedade perceptiva seletiva, 6 a quantitativa, 2 a ordenada e 6 mista (Quadro 2).

\begin{tabular}{|c|c|c|c|c|c|}
\hline $\begin{array}{l}\text { Propriedade } \\
\text { perceptiva }\end{array}$ & $\begin{array}{c}\text { Método de } \\
\text { representação }\end{array}$ & Mapa & $\begin{array}{c}\text { Número } \\
\text { de } \\
\text { Mapas }\end{array}$ & Implantação & Página \\
\hline Seletiva & Quantitativa & $\begin{array}{l}\text { Corocromático e } \\
\text { manifestação pontual } \\
\text { e linear }\end{array}$ & 11 & $\begin{array}{l}\text { Zonal, linear e } \\
\text { ou pontual }\end{array}$ & $\begin{array}{c}45,48, \\
49,62,96 \\
143,218, \\
255,258, \\
261,264\end{array}$ \\
\hline Associativa & Qualitativa & $\begin{array}{l}\text { Corocromático e } \\
\text { manifestação pontual } \\
\text { e linear }\end{array}$ & - & - & - \\
\hline Ordenada & $\begin{array}{l}\text { Qualitativa e ou } \\
\text { dinâmica } \\
\text { /cronológica }\end{array}$ & $\begin{array}{c}\text { Corocromático e } \\
\text { manifestação pontual } \\
\text { e linear }\end{array}$ & 2 & Zonal & 112,271 \\
\hline \multirow{4}{*}{ Quantitativa } & \multirow{4}{*}{ Quantitativo } & Coroplético & 2 & Zonal & 167,194 \\
\hline & & Isarítimico & 6 & $\begin{array}{c}\text { Linear e ou } \\
\text { Zonal }\end{array}$ & $\begin{array}{c}16,58,61 \\
91,135 \\
\end{array}$ \\
\hline & & Pontos de contagem & 1 & Pontual & 201 \\
\hline & & $\begin{array}{c}\text { Figuras geométricas } \\
\text { proporcionais }\end{array}$ & 1 & Pontual & 218 \\
\hline Mista & Misto & Misto & 4 & $\begin{array}{c}\text { Pontual, } \\
\text { linear e ou } \\
\text { zonal }\end{array}$ & $\begin{array}{l}212,213, \\
225\end{array}$ \\
\hline
\end{tabular}

Os temas mais frequentes tratados na percepção seletiva foram: as grandes navegações no mundo, questões geopolíticas, aspectos físicos no mundo e disponibilidade de recursos minerais. A percepção quantitativa foi bastante explorada, utilizando os métodos coroplético para a representação da distribuição do PIB e da fome no mundo, o método isarítimico para a representação fenômenos naturais, e as figuras geométricas proporcionais para a representação do crescimento financeiro. Somente o método de pontos de 
contagem não foi contemplado neste volume. No caso da percepção mista, apenas aspectos geopolíticos e de produção industrial são contemplados.

Quadro 2: Mapas do livro Fronteiras da Globalização 2

\begin{tabular}{|c|c|c|c|c|c|}
\hline $\begin{array}{l}\text { Propriedade } \\
\text { perceptiva }\end{array}$ & $\begin{array}{c}\text { Método de } \\
\text { representação }\end{array}$ & Mapa & $\begin{array}{c}\text { Número } \\
\text { de } \\
\text { Mapas }\end{array}$ & Implantação & Página \\
\hline Seletiva & Quantitativa & $\begin{array}{c}\text { Corocromático e } \\
\text { manifestação } \\
\text { pontual e linear }\end{array}$ & 26 & $\begin{array}{l}\text { Zonal, linear } \\
\text { e ou pontual }\end{array}$ & $\begin{array}{l}11,14,26,33, \\
43,80,85,90, \\
91,113,151, \\
155,167,173, \\
178,180,201, \\
212,229,247, \\
248,249,253, \\
255,263,276 .\end{array}$ \\
\hline Associativa & Qualitativa & $\begin{array}{c}\text { Corocromático e } \\
\text { manifestação } \\
\text { pontual elinear }\end{array}$ & - & - & . \\
\hline Ordenada & $\begin{array}{l}\text { Qualitativa e ou } \\
\text { dinâmica } \\
\text { /cronológica }\end{array}$ & $\begin{array}{c}\text { Corocromático e } \\
\text { manifestação } \\
\text { pontual linear e } \\
\text { ou zonal }\end{array}$ & 2 & Zonal & 23,185 \\
\hline \multirow{4}{*}{ Quantitativa } & \multirow{4}{*}{ Quantitativo } & Coroplético & 2 & Zonal & 60,63 \\
\hline & & Isarítimico & 1 & Zonal & 194 \\
\hline & & $\begin{array}{l}\text { Pontos de } \\
\text { contagem }\end{array}$ & - & - & - \\
\hline & & $\begin{array}{l}\text { Figuras } \\
\text { goométricas } \\
\text { proporcionais }\end{array}$ & 3 & Pontual & 41,275 \\
\hline Mista & Misto & Misto & 6 & $\begin{array}{l}\text { Pontual, } \\
\text { lineare e ou } \\
\text { zonal }\end{array}$ & $\begin{array}{r}28,32,136, \\
166,191,274 .\end{array}$ \\
\hline
\end{tabular}

\subsection{Os mapas}

Como forma de ilustrar os métodos de representação apresentados nos livros, foram selecionados por meio de critérios intensionais de diversidade alguns mapas dentre os vários registrados. Entre os vários métodos, os mais utilizados são os que adotam critérios seletivos (representação qualitativa), ou seja, buscam segregar, separar em áreas distintas a informação que se quer representar. A variável visual mais utilizada é a cor, que neste caso, são distintas entre si, não podendo haver nenhuma hierarquia entre elas, pois cada uma representa uma informação que não está relacionada à outra.

O mapa da figura 3 ilustra as regiões conflitantes na Ásia, Índia, Paquistão e China que são representadas por cores distintas.

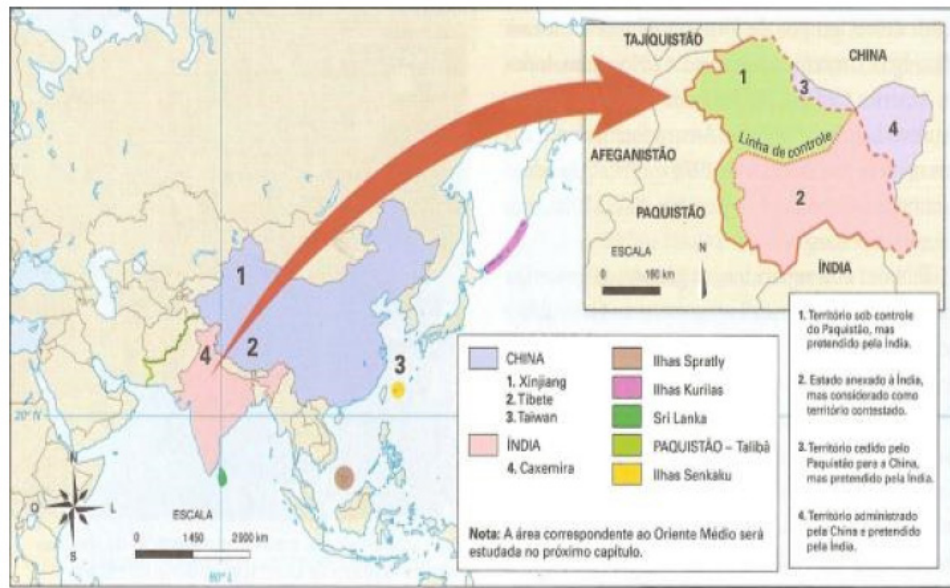

Figura 3: Conflitos na Ásia.

Fonte: Livro Fronteiras da Globalização 1, pág. 264
Apesar da percepção adotada ser seletiva, nota-se na legenda que há uma hierarquia entre as cores verde, verde claro e amarelo que são cores análogas, ou seja, aparecem uma do lado da outra no círculo de cores, transmitindo assim uma ideia de ordenamento. Uma forma de corrigir este problema seria a simples substituição do verde claro pela cor vermelha que interromperia a sequência de cores enfatizando a seletividade da informação.

Diferentemente do método seletivo, o método ordenado tem a função de transmitir uma ordem e dependência entre as informações que representa. O mapa de desertificação no mundo (Figura 4) apresenta esse método de maneira adequada, pois utiliza cores quentes análogas indicando a ideia de sequência para representar o avanço da desertificação. Ao utilizar a sequência de cores corretamente, ao ler a legenda mesmo que rapidamente, pode-se identificar a localização e a intensidade do evento nas diversas regiões do mundo. Outro ponto importante, é que para indicar as regiões não atingidas pela desertificação, foram utilizadas cores frias, facilitando a interpretação das informações transmitidas.

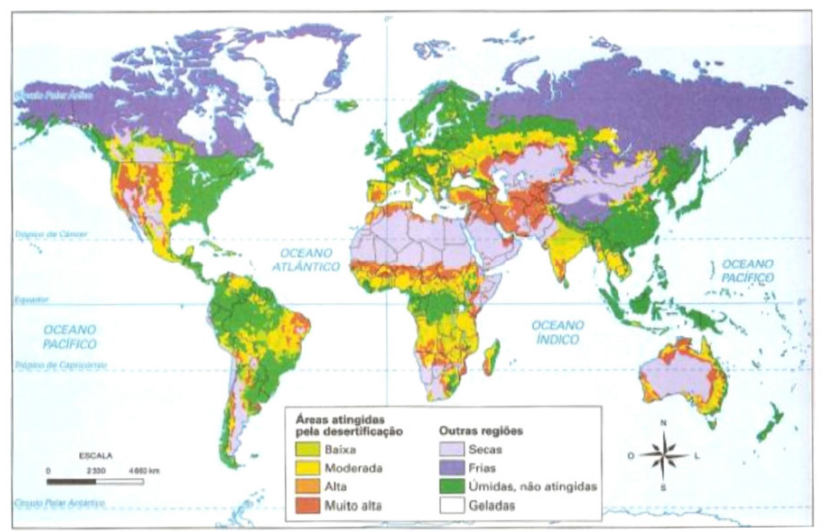

Figura 4: Desertificação no mundo.

Fonte: Livro Fronteiras da Globalização 1, pág. 112.

Vale destacar que a correta utilização das cores neste mapa e a organização de sua legenda tornam-no de fácil leitura. É possível inferir rapidamente as regiões mais quentes do planeta como o nordeste brasileiro, o oeste dos Estados Unidos e a maior parte do continente africano. $\mathrm{O}$ fator climático é um grande colaborador para o avanço da desertificação que, como se pode notar, ocorre nas regiões mais quentes, porém as atividades humanas também têm grande influência nesse processo, como a derrubada de florestas para a formação de pastagens, o mau uso do solo na agricultura e o assoreamento dos rios. 
A propriedade perceptiva ordenada com o uso de cores, quando bem empregada, facilita muito a interpretação de fenômenos que ocorrem ao longo dos anos, pois o escalonamento das cores proporciona a ideia de movimento e de tempo. A Figura 5 ilustra um exemplo de ordenamento ao longo do tempo.

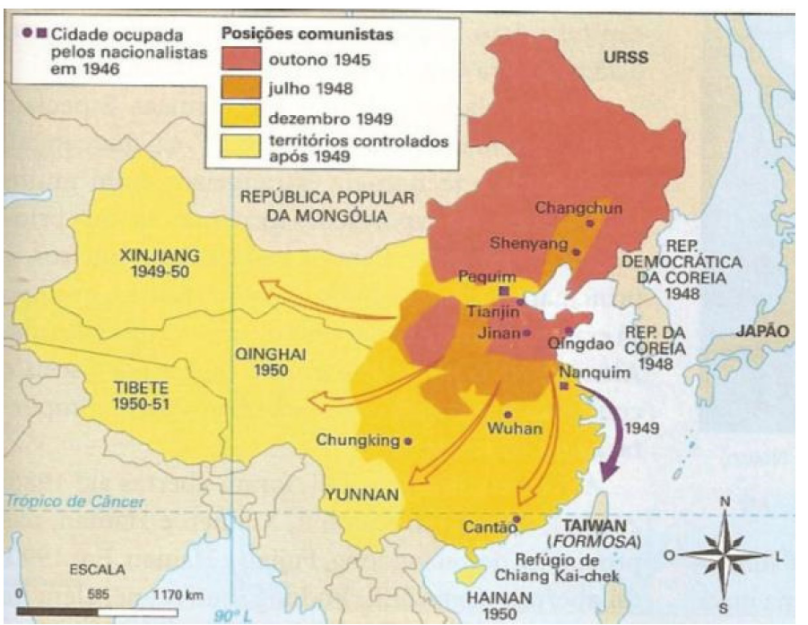

Figura 5: A vitória comunista (1946 - 1949).

Fonte: Livro Fronteiras da Globalização 2, pág. 185.

Este mapa demonstra o avanço, ao longo dos anos, do Partido Comunista chinês liderado por Mao Tse-tung após vitória sobre o Partido Nacionalista, liderado por Chiang Kai-chek. A evolução dos comunistas sobre o território chinês é ilustrada com o auxílio das cores vermelhas, indicando o período mais antigo, laranja, amarelo escuro e amarelo claro indicando o período mais recente, além de setas indicando a direção do avanço. Após a derrota, os membros do Partido Nacionalista se deslocaram para a ilha de Formosa (Taiwan), como demonstra a seta de cor roxa no mapa.

Diferentemente da Figura 5, onde foram utilizadas sequencias de cores em harmonia que com a sequência dos eventos, a Figura 6 ilustra outro exemplo de cronologia, porém com adoção de cores equivocadas. $\mathrm{O}$ referido mapa ilustra a anexação de território vizinhos à União Soviética, criada em 1922 após a primeira revolução socialista da história: a Revolução Russa de 1917, até a década de 1940. A utilização de cores distintas para representar a percepção de ordenamento faz com que a leitura do mapa seja comprometida e "amarrada" na codificação das cores. Além disso, as caixas da legenda inseridas lateralmente ressaltam ainda mais a descontinuidade do evento.

Para a representação de fenômenos quantitativos são utilizados, na maioria das vezes, mapas coropléticos, isarítimicos, de pontos de contagem e de figuras geométricas pro- porcionais. A Figura 7 corresponde a um mapa coroplética que ilustra com sequência de cores a distribuição de riqueza no mundo. Os a países com o Produto Interno Bruto (PIB) mais baixos são representados pela cor vermelha e os países com o PIB mail alto com a cor verde escuro. Ao analisar o mapa, fica clara a extrema desigualdade entre aos países africanos em relação aos países da Europa Ocidental e América do Norte. Países que estão abaixo da chamada linha que divide o mundo entre Norte e Sul são os que apresentam maiores problemas. Fatores históricos como a colonização de exploração, deixaram sequelas até os dias atuais como a fraca industrialização, infraestrutura precária das vias de transporte e a baixa capacitação educacional e técnica dos trabalhadores.

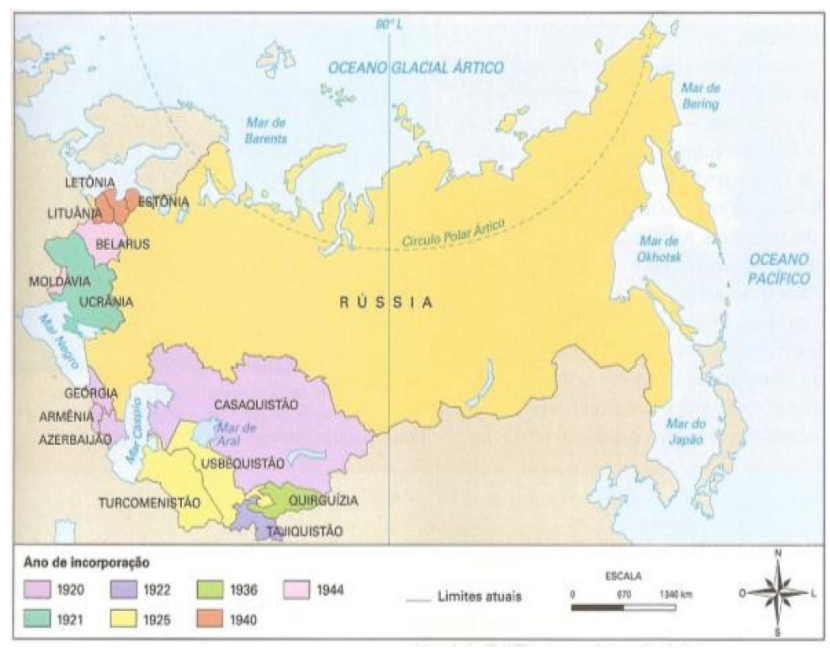

Figura 6: A formação e a expansão da URSS

Fonte: Livro Fronteiras da Globalização 2, pág. 23.

Os mapas isarítimicos, são geralmente utilizados para a representação de fenômenos contínuos como precipitação, altimetria, temperatura e profundidade. A variável visual mais utilizada é o valor, que consiste na variação de tonalidade de uma cor utilizada, que se obtém acrescentando ou removendo o branco da cor selecionada. A legenda é apresentada normalmente em caixas juntas transmitindo uma maior percepção de continuidade. A Figura 8 ilustra as precipitações no mundo nos meses de janeiro e junho. Conforme pode ser observados, os países com maiores precipitações encontram-se próximos a linha do Equador em função da atuação dos ventos alísios que se encontram trazendo grande umidade para a região. Apesar da qualidade dos mapas, estes poderiam ser aperfeiçoados utilizando a cor azul para representar a precipitação, tornando assim a leitura do mapa mais intuitiva. 


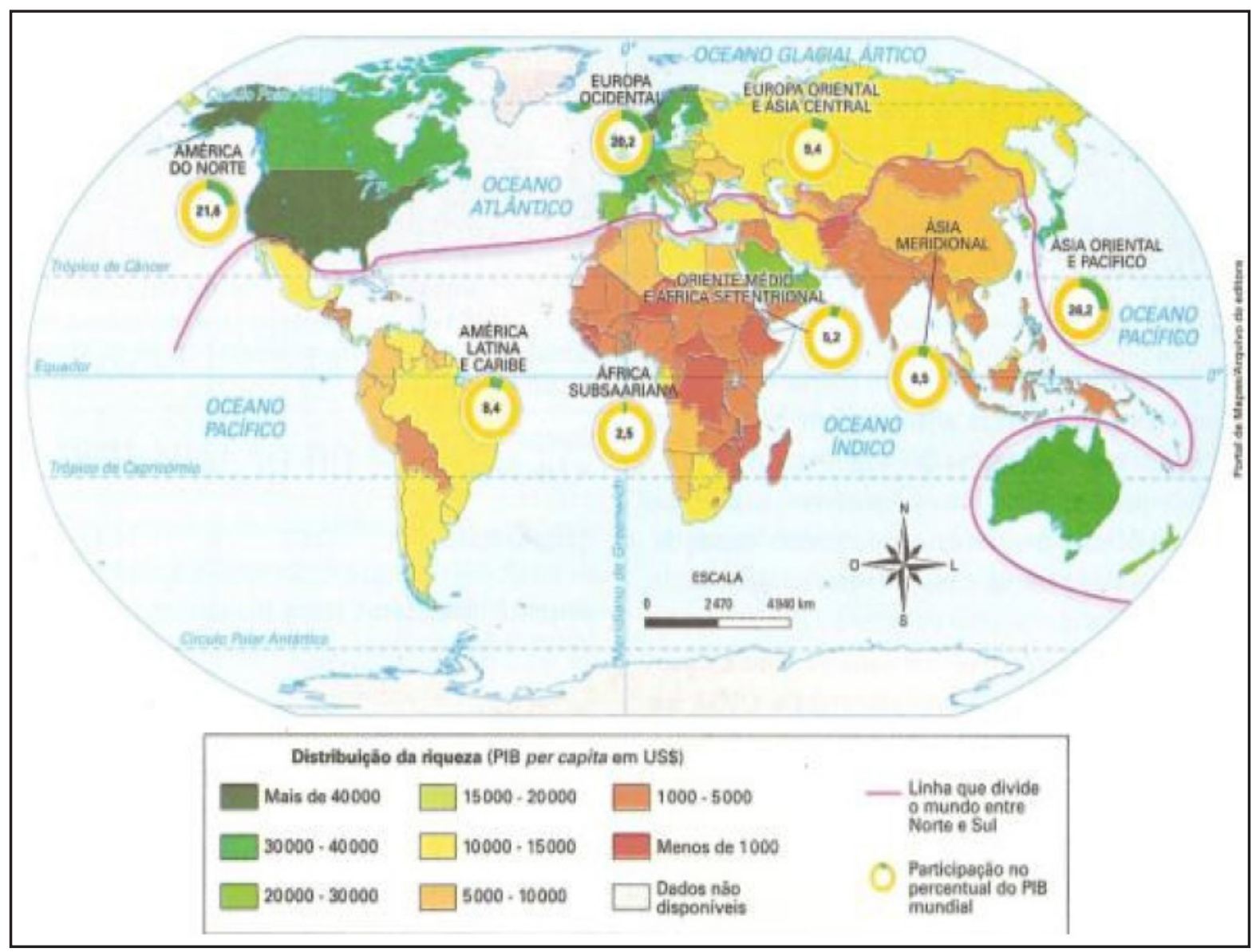

Figura 7: Distribuição do PIB mundial.

Fonte: Livro Fronteiras da Globalização 2, pág. 60.

Os valores absolutos são representados basicamente pelos métodos de pontos de contagem e figuras geométricas proporcionais. A Figura 9 ilustra a implantação e expansão de uma cadeia de restaurantes dos Estados Unidos utilizando o método de figuras geométricas proporcionais. Ao realizar a leitura do mapa, é possível observar que a maior da cadeia de restaurantes ocorreu nos países da Europa e na China. O Japão, apesar de possuiu um grande número de estabelecimentos, apresentou retração, assim como no caso do Brasil. Um ponto que merece ser destacado neste mapa é a complexidade da sua leitura, pois além de analisar o número de estabelecimentos, o mapa também fornece a informação de crescimento e de retração dessa cadeia representada por duas cores opostas.

A Figura 10 utiliza o método de pontos de contagem para representar a distribuição da população no mundo.
Neste mapa, observa-se que as regiões mais povoadas se encontram próximas ao litoral, isto por apresentar, entre outras, condições naturais mais propícias às atividades humanas como planícies mais férteis e proximidade dos portos para escoamento da produção industrial e agrícola. A Índia, com sua imensa população apresenta seu território quase que completamente ocupado, ao contrário da China que apesar de possuir a maior população do mundo, esta se encontra concentrada em sua região litorânea.

O método de representação misto utiliza-se de dois ou mais métodos para a representação do fenômeno, o que requer uma maior abstração do leitor. A Figura 11 ilustra a produção, venda e exportação da marca de veículos japonesa Toyota no ano de 2009. É possível inferir por meio do tamanho do círculo que a maior produção de veículos se encontra no Japão, onde se localiza a sede da empresa, e que a maior evolução de suas exportações ocorreu com destino ao orien- 
te médio. O maior número de vendas ocorreu na América do Norte seguido da Europa e a maior evolução na porcentagem de vendas ocorreu na Ásia. Este tipo de mapa apresenta uma grande quantidade de informação o que o torna complexo, exigindo um maior conhecimento do aluno. Para sua leitura, é preciso analisar as cores dos círculos, tamanho, números inseridos, as larguras e cores das setas que indicam um maior ou menor fluxo.

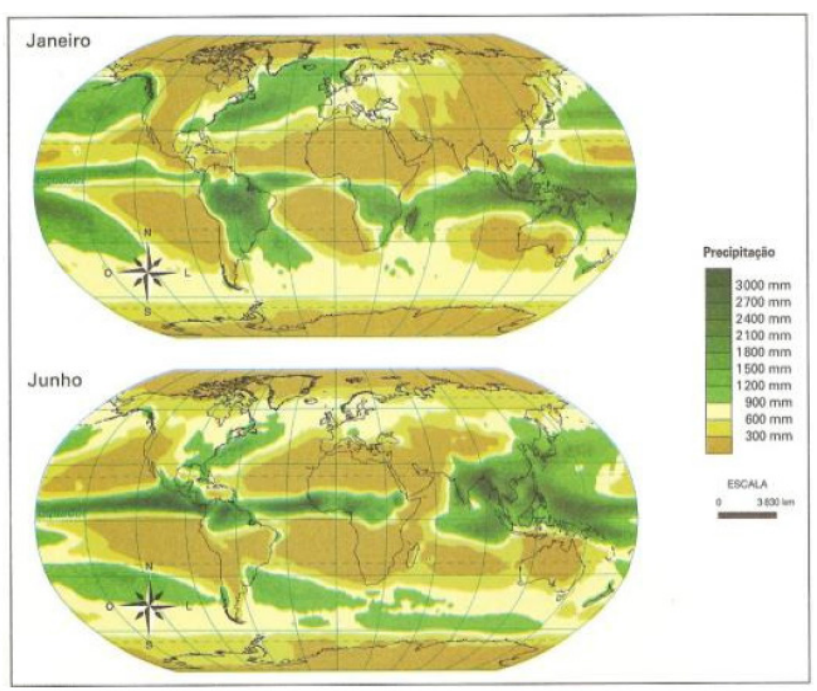

Figura 8: Precipitações no mundo.

Fonte: Livro Fronteiras da Globalização 1, pág. 135.

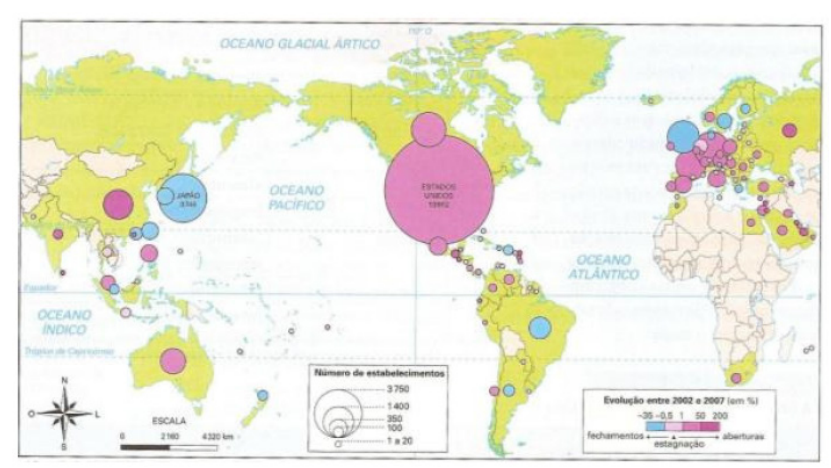

Figura 9: Implantação e expansão de uma transnacional do setor terciário (2002-2007).

Fonte: Livro Fronteiras da Globalização 2, pág. 275.

Um exemplo de mapa de fácil interpretação é o que utiliza ícones, chamados de figuras pictóricas. A Figura 12 mostra as espécies de plantas e animais ameaçados de extinção. Neste mapa, as espécies foram divididas em grupos de maneira análoga ao método associativo e estes receberam ícones. Os hotspots são zonas de diversidade biológicas muito ricas, os animais e vegetais ameaçados são representados por áreas circuladas em vermelho. O excesso e a má utiliza- ção dos recursos naturais, principalmente pelas grandes potências, colocam em risco a diversidade da vida no planeta. A América do Sul, conhecida mundialmente por abrigar a floresta amazônica também não está imune aos riscos ecológicos causados pela degradação dos recursos naturais. É possível constatar no mapa que a maior quantidade de anfibios e plantas ameaçadas de extinção se encontra nesta região.

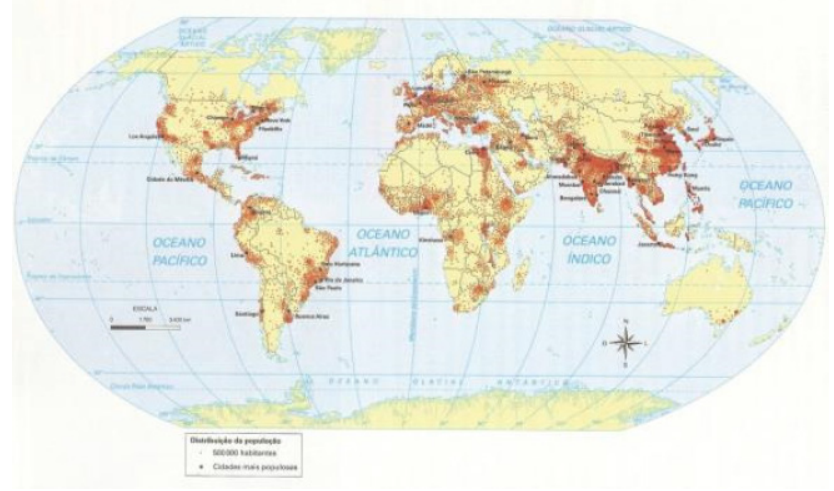

Figura 10: Distribuição da população no mundo.

Fonte: Livro Fronteiras da Globalização 1, pág. 201.

Para a representação de recursos minerais e de localização de indústrias, geralmente é utilizado o mapa conhecido como exaustivo. Este modo de representação recebe este nome por ter sua leitura cansativa, pois vários atributos são dispostos sobre um mesmo mapa, requerendo do leitor a recorrência à legenda tornando sua leitura esgotante. A Figura 13 mostra a distribuição de minérios na China. Para cada minério, um símbolo é adotado. Uma maneira de tornar a leitura deste mapa menos cansativo é a adoção de uma coleção de mapas. Para cada minério, um mapa é construído.

\subsection{O conteúdo teórico e os mapas}

O mapa como instrumento de linguagem espacial deve auxiliar na interpretação do fenômeno geográfico de modo que esteja em consonância com o conteúdo teórico apresentado.

Sobre a importância do texto para o mapa:

\footnotetext{
O mapa e o texto são ambos indispensáveis. Apoiam-se mutuamente, pois um revela configurações territoriais invisíveis na tabela estatística, enquanto o outro promove a relação dessas configurações com os processos que lhe deram nascimento. Os processos sociais, seus atores e suas lógicas não aparecem no mapa, mas possuem uma dimensão espacial que o mapa revela (THÉRY; MELLO, 2009, p. 14).
} 


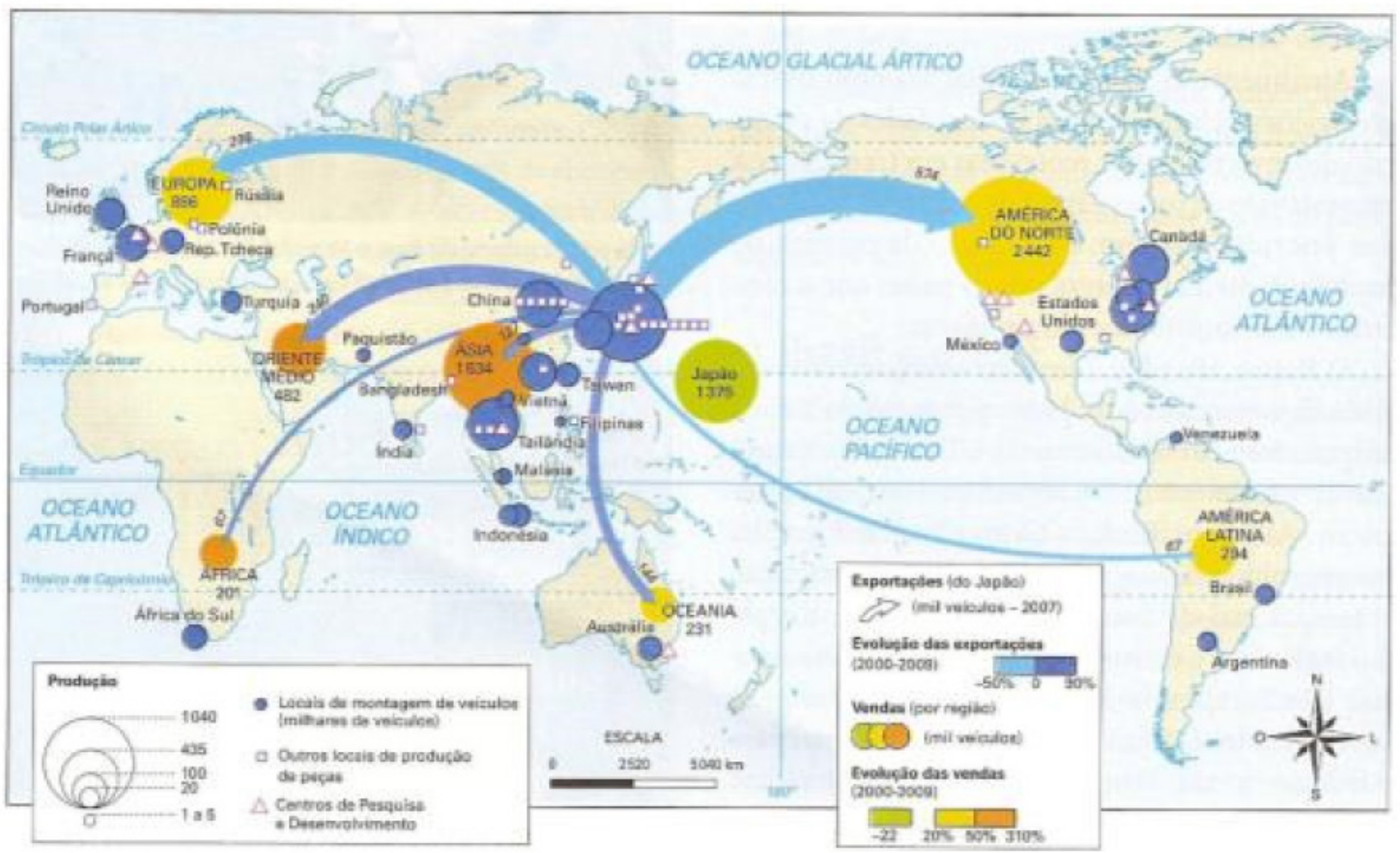

Figura 11: Produção e venda de empresa automobilística (2009).

Fonte: Livro Fronteiras da Globalização 2, pág. 274.

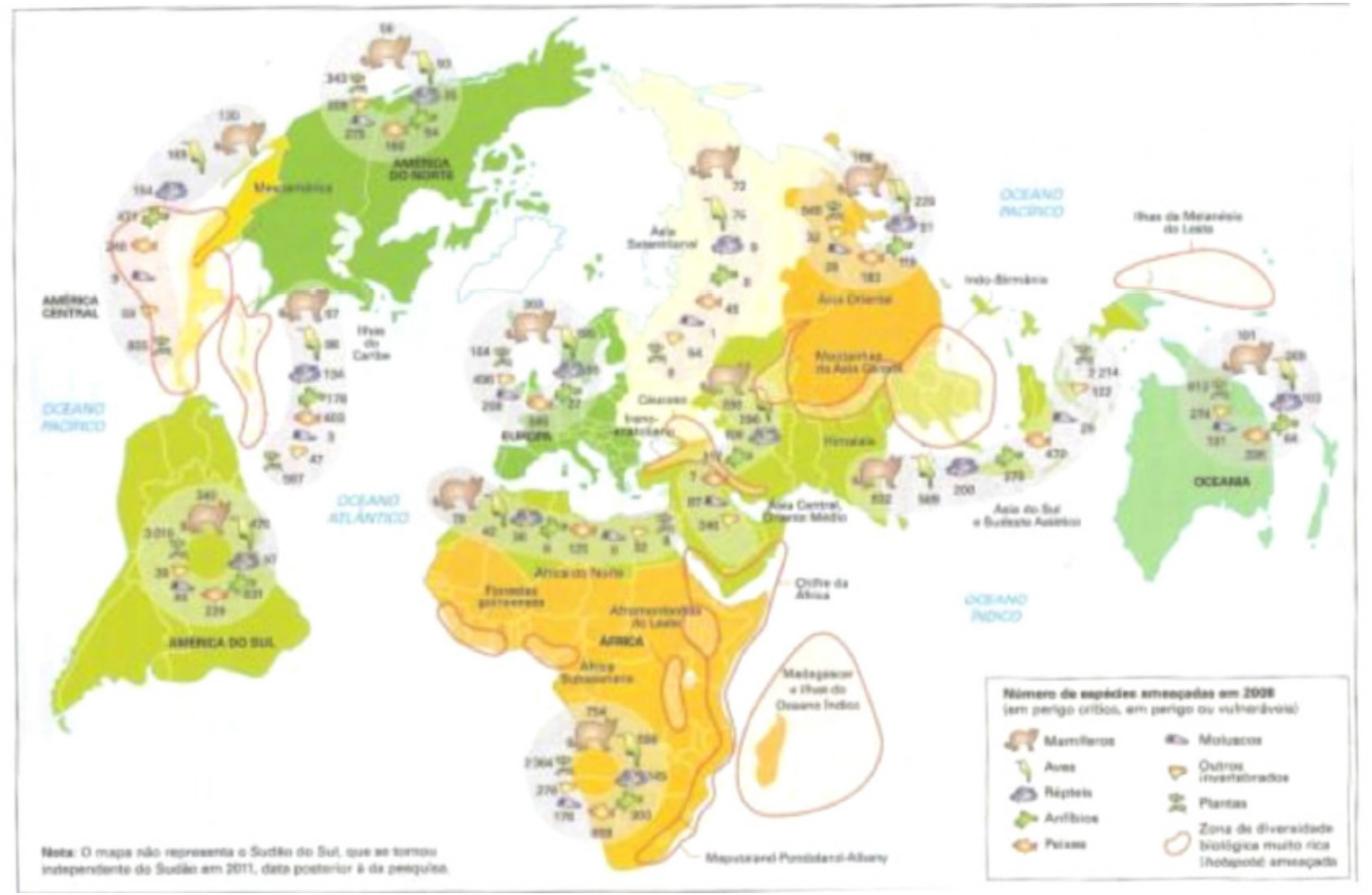

Figura 12: Riscos ecológicos.

Fonte: Livro Fronteiras da Globalização 1, pág. 225.

Geografia, Ensino \& Pesquisa, Vol. 20 (2016), n.3, p. 63-77

ISSN: 2236-4994 DOI: 10.5902/2236499419279 
Deste modo, compreende-se a importância que o texto possui, pois é ele quem vai apontar os detalhes e minúcias que não estão explícitos nos mapas. Assim é importante que o texto seja coerente e que chame a atenção e convide o leitor a explorar o mapa que ilustra seu conteúdo.

De maneira geral, os dois livros analisados apresentam conteúdos teóricos relevantes no ensino de geografia, quase sempre acompanhado de mapas, tabelas e cartogramas, o que enriquece a leitura e o aprendizado.

Os assuntos abordados no livro são complementados no próprio material didático com matérias extraídas de revistas e jornais de grande circulação que ajudam estabelecer uma relação entre o assunto e o cotidiano, além de textos de grandes pensadores da geografia como o professor Milton Santos. Outro ponto positivo é a indicação de filmes, livros e sites que contemplam os assuntos que estão sendo estudados.

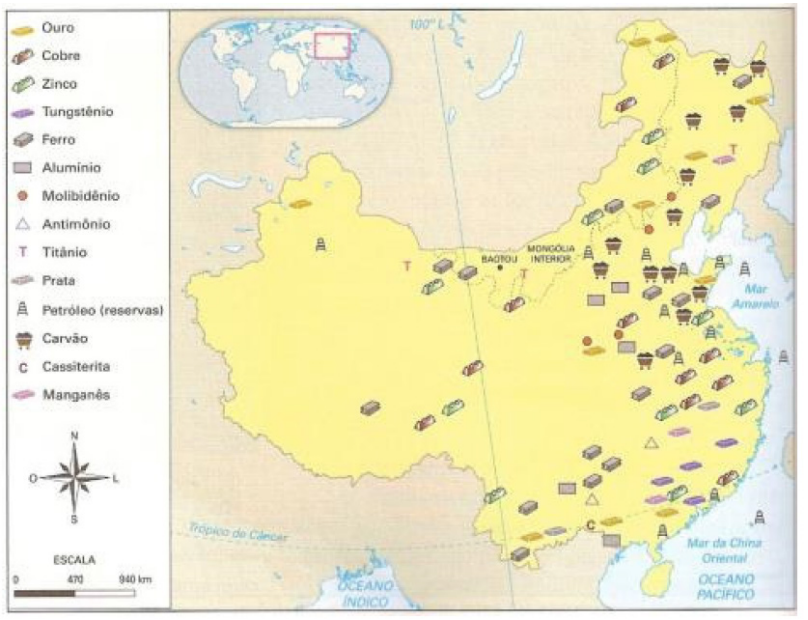

Figura 13: China: recursos minerais.

Fonte: Livro Fronteiras da Globalização 2, pág.188.

São também apresentados no decorrer do livro, textos que trazem uma visão diferente do assunto que está sendo estudado, proporcionando ao aluno outro ponto de vista. Assim, é possível que se compreenda que há diversas visões sobre o mesmo assunto e que cabe ao leitor analisar e buscar novas fontes de conhecimento para formar sua opinião.

Temas para pesquisas, questões para reflexão e atividades interdisciplinares também são sugeridas, levando o aluno a se tornar um “jovem pesquisador", pois deverá buscar em outras disciplinas ajuda para resolver os problemas propostos.

Com o intuito de preparar os estudantes para o ingresso no curso superior, ao final de cada unidade, uma série de questões do Exame Nacional do Ensino Médio (ENEM) e de vestibulares é apresentada, facilitando a compreensão da maneira como os conteúdos geográficos são cobrados em tais provas, mas, observa-se uma incongruência, já que os PCNs destacam que o ingresso no mercado de trabalho e no ensino superior não deve ser o principal elemento do ensino de geografia e sim a construção de uma consciência social.

Nesta perspectiva, as questões do ENEM são tão necessárias ao livro didático? Se o objetivo é ensinar o aluno a pensar, esse tipo de "treinamento" não fica distante do que defendem os PCNs? Esta é uma questão a ser aprofundada em outra oportunidade, o que se verifica, é que no dia a dia de um mercado profissional tão qualificado e competitivo este recurso apresenta-se interessante, pois proporciona aos alunos um contato com os métodos de seleção utilizados para o ingresso no curso superior e talvez os PCN's após mais de uma década de sua elaboração necessitem sofrer algumas reformulações ditas contemporâneas.

Outros pontos negativos também foram observados. Alguns textos não fazem referência ao mapa que os acompanha e muitas vezes não são ao menos citados. Isso é uma grande falha, pois muitos destes mapas são de excelente qualidade e poderiam ser mais bem explorados, despertando assim um maior interesse e afinidade do aluno com essa importante ferramenta. Sabe-se que a exploração do mapa deve ser conduzida pelo professor, mas o material didático também tem a tarefa de conduzir a análise exploratória por meio de textos informativos, que podem auxiliar na compreensão do mesmo e ao mesmo tempo constituir fonte de pesquisa para os alunos.

O fato de muitos mapas não serem explorados da maneira que poderiam, dá certa impressão de que muitos deles são utilizados apenas como instrumento de localização. Habilidades mais complexas que requerem raciocínios de ordem, cronologia, proporcionalidade, adensamento e inferência não são nem menos referidos em alguns textos, apesar de vários mapas apresentados permitirem o desenvolvimento de tais raciocínios.

Vale a pena aqui destacar que muitos dos mapas apresentados foram extraídos de atlas franceses, que são referência de qualidade quando se refere à cartografia temática. Talvez, essa seja uma das maiores falhas dos livros didáticos! Os mapas são Geográficos e não didáticos. O objetivo do Atlas não é o mesmo do livro. Os mapas do livro devem ser construídos para o livro levando em conta o nível de desenvolvimento do aluno.

Outro ponto que merece ser destacado refere-se ao desequilíbrio de métodos cartográficos empregados na ilustração dos diversos temas geográficos abordados. Há 
um domínio dos métodos de representação de fenômenos qualitativos e mesmo havendo tal predominância, há poucas variações na forma como o conteúdo é apresentado. Para representar a localização de minérios ou de indústrias, é utilizado apenas o método exaustivo, sendo que estes poderiam ser perfeitamente substituídos pelo método de coleção de mapas.

Desta maneira, ao invés de sobrepor todos os minérios em um único cartograma, coleções poderiam ser montadas levando em consideração a localização de minerais metálicos e não metálicos ou aqueles de maior ou menor valor comercial, por exemplo.

Com relação aos métodos quantitativos, apesar dos pontos de contagem serem bastante eficientes na distribuição e adensamento de fenômenos, este foi utilizado apenas em um único mapa para a representação da população no mundo, sendo que poderia ser utilizado em vários assuntos relacionados tanto a geografia humana como física.

\section{CONSIDERAÇÕES FINAIS}

Os dois livros analisados tratam de assuntos relevantes no ensino de geografia e são bem ilustrados, com mapas, cartogramas, tabelas e gráficos. A análise do conteúdo apresentado nos dos dois volumes, mostra também que estes estão de acordo com os PCN's, constituindo, portanto, uma referência importante no ensino de geografia.

Os resultados mostraram que no geral, há um forte desequilíbrio de métodos cartográficos empregados. Apesar da qualidade dos livros, alguns pontos negativos com relação à cartografia temática e a metodologia de Bertin (1967) foram constatados. Verificou-se um forte desequilibrio de metodologias cartográficas empregadas na espacialização de diferentes temas da geografia.

Também foi observada uma fraca conexão do conteúdo teórico com os mapas apresentados, sendo estes mais utilizados como instrumento de localização do que como uma metodologia de ensino que explora a comunicação visual.

A utilização do mapa no ensino de geografia é crucial, pois o mapa permite que aluno se desvencilhe da conceituação simplista de que o aprendizado da geografia é amarrado à memorização de conteúdo enfadonho e desvinculado de uma lógica espacial. O mapa, desta forma, quando elaborado corretamente e interpretado da maneira que se deve, permite o usuário exercitar inúmeras habilidades de localização, descrição, relacionamento entre partes e inferência com base em evidências espaciais cartesianas ou não.

\section{REFERÊNCIAS BIBLIOGRÁFICAS}

ALMEIDA, Lúcia Marina Alves de.; TÉRCIO, Barbosa Rigolin. Fronteiras da Globalização 1: O mundo natural e o espaço humanizado. 2. ed. São Paulo: Editora Ática, 2014.

ALMEIDA, Lúcia Marina Alves de.; TÉRCIO, Barbosa Rigolin. Fronteiras da Globalização 2: O espaço geográfico globalizado. 2. ed. São Paulo: Editora Ática, 2014.

ARCHELA, Rosely Sampaio.; THÉRY, Hervé. Orientação metodológica para construção e leitura de mapas temáticos. Confins [online], n. 3, 2008. Disponível em: <http://confins.revues.org/3483> Acesso em: 27/08/2015.

BERTIN, Jacques. Sémiologie Graphique: Les diagrammes, les réseaux, les cartes. Paris, La Haye: Mouton, Gauthier-Villars, 1967.

BRASIL. Lei $\mathrm{n}^{\circ}$ 9.394, de 20 de Dezembro de 1996. Estabelece as diretrizes e bases da educação nacional. Disponível em: < http://www.planalto.gov.br/ccivil_03/leis/ 19394.htm>. Acesso em: 14 abr. 2015.

BRASIL. Ministério da Educação. Secretaria de Educação Média e Tecnológica. Parâmetros Curriculares Nacionais (Ensino Médio). Brasilia: MEC, 2000.

BRASIL. Ministério da Educação. Secretaria da Educação Média e Tecnológica. Parâmetros Curriculares Nacionais + $(\mathrm{PCN}+)$ - Ciências da Natureza e suas Tecnologias. Brasília: MEC, 2002.

GOUVEIA, Magali. Combinando as Cores - Círculo Cromático. Disponível em: < http://www.amopintar. com/harmonia-das-cores/>. Acesso em: 27/08/2015.

JOLY, Fernand. Cartografia. $8^{\mathrm{a}}$ ed. Campinas/SP: Editora Papirus, 2005. 136 p.

MARTINELLI, Marcello. Curso de Cartografia Temática. Contexto: São Paulo, 1991. 180p.

MARTINELLI, Marcello. Mapas da Geografia e cartografia temática. $1^{\mathrm{a}}$ ed. São Paulo/SP: Editora Contexto, 2003. 112 p.

THÉRY, Hervé; MELLO, Neli Aparecida de. Atlas do Brasil: Disparidades e Dinâmicas do Território. 2.ed., 1. reimpr. São Paulo: Editora da Universidade de São Paulo, 2009. 


\section{Correspondência dos autores:}

Fernando da Silva Alves

e-mail: preto-preto@hotmail.com

Fernando Sbinji Kawakubo

e-mail: fskgeo@gmail.com

Felipe Gomes Rubira

e-mail: felipe_rubira@hotmail.com

Artigo recebido em: 31/08/2015

Revisado pelos autores em: 28/04/2016

Aceito para publicação em: 14/08/2016 